\title{
A Review on Coating \& Lamination in Textiles: Processes and Applications
}

\author{
Kunal Singha \\ Department of Textile Technology, Panipat Institute of Engineering \& Technology, Harayana, India
}

\begin{abstract}
Coating and lamination are two functional processes which are used make a proper finishing to the textile material. The coating formulation with different textile grade polymer like PVC, PU, acrylic, PTFE are hugely used to make a textile product with multipurpose way like- waterproof protective clothing, tarpaulin, protective clothing, electrical insulation etc. on the other hand lamination process is used to prepare some important textile products with daily uses in our practical life like- blackout curtains and blinds, and c. In this current work is related to details of lamination theory, various processes, formulations, application, recent developments of the coating and lamination in the textile field.
\end{abstract}

Keywords Coating, Lamination, PVC, PU, Acrylic, Waterproof Protective Clothing, Tarpaulin, Tarpaulin, Lamination Theory, Processes, Formulations, Application, Recent Developments

\section{Introduction}

Coating and laminating are increasingly important techniques for adding value to technical textiles. Coating and lamination enhance and extend the range of functional performance properties of textiles and the use of these techniques is growing rapidly as the applications for technical textiles become more diverse. Cheaper fabric structures may be coated or laminated to provide higher added value to end-users and higher profit margins to manufacturers. The key to success in textile coating and lamination depends upon the application of appropriate technology using modern machinery[1-3]. Machine productivity is important, but flexibility in terms of production speed and the versatility of coating/lamination methods are important factors to consider, as well as a high level of process monitoring, process control and automation to satisfy demanding technical specifications.

\section{Coating Technology}

Coating is a process in which a polymeric layer is applied directly to one or both surfaces of the fabric. The polymer coating must adhere to the textile and a blade or similar aperture controls the thickness of the viscous polymer. The coated fabric is heated and the polymer is cured (that is, polymerized). Where a thick coating is required this may be built up by applying successive coating layers, layer on

\footnotetext{
* Corresponding author:

kunalsingha28@gmail.com (Kunal Singha)

Published online at http://journal.sapub.org/ajps

Copyright (C) 2012 Scientific \& Academic Publishing. All Rights Reserved
}

layer,Interlayer adhesion must therefore be high[2]. Finally, a thin top layer may be applied for aesthetic or technical enhancement of the coating. Depending upon the end-use requirements, heavy-duty technical textile coatings may be applied at high weight, while other end-uses for high- technology apparel may require coating weights very low. The chemical formulation of the coating, the coating thickness and weight, the number of layers, the form of the technical textile and the nature of any pre-treatment (such as to stabilize the fabric dimensions prior to coating) are of great importance. Traditionally, coating has been applied to woven technical textiles, but increasingly warp-knitted, raschel[3], weft-knitted and nonwoven fabrics must be coated on the same line. The machinery and method of application of the coating formulation must be versatile, minimize tensions on the fabric that may lead to distortion or stretch, and eliminate problems in knitted fabrics such as curling selvedges. Scroll opening equipment, weft straightening, tension bars and selvedge uncurlers may thus be fitted[4-6]. The lighter the weight of the technical textile the more prone will be the base fabric for coating to weft line distortion and selvedge curling.

\subsection{Coating Formulations}

The formulation of a coating is complicated, and it can contain a wide range of chemicals depending upon the nature of the polymer, the necessary additives for the specific end use, whether the coating has to be foamed prior to application, and the type of coating machinery to be used. Coatings may be coloured, translucent or opaque, fluorescent, photoluminescent or retro-reflective, according to the end user requirements[7]. Some thermoplastics are used as they allow the material to be used as they allow the material to be used as hot melt adhesive and in some cases for welding techniques. They are used as coating polymers. 
Table 1. Some of the useful applications of coating[1,7-9]

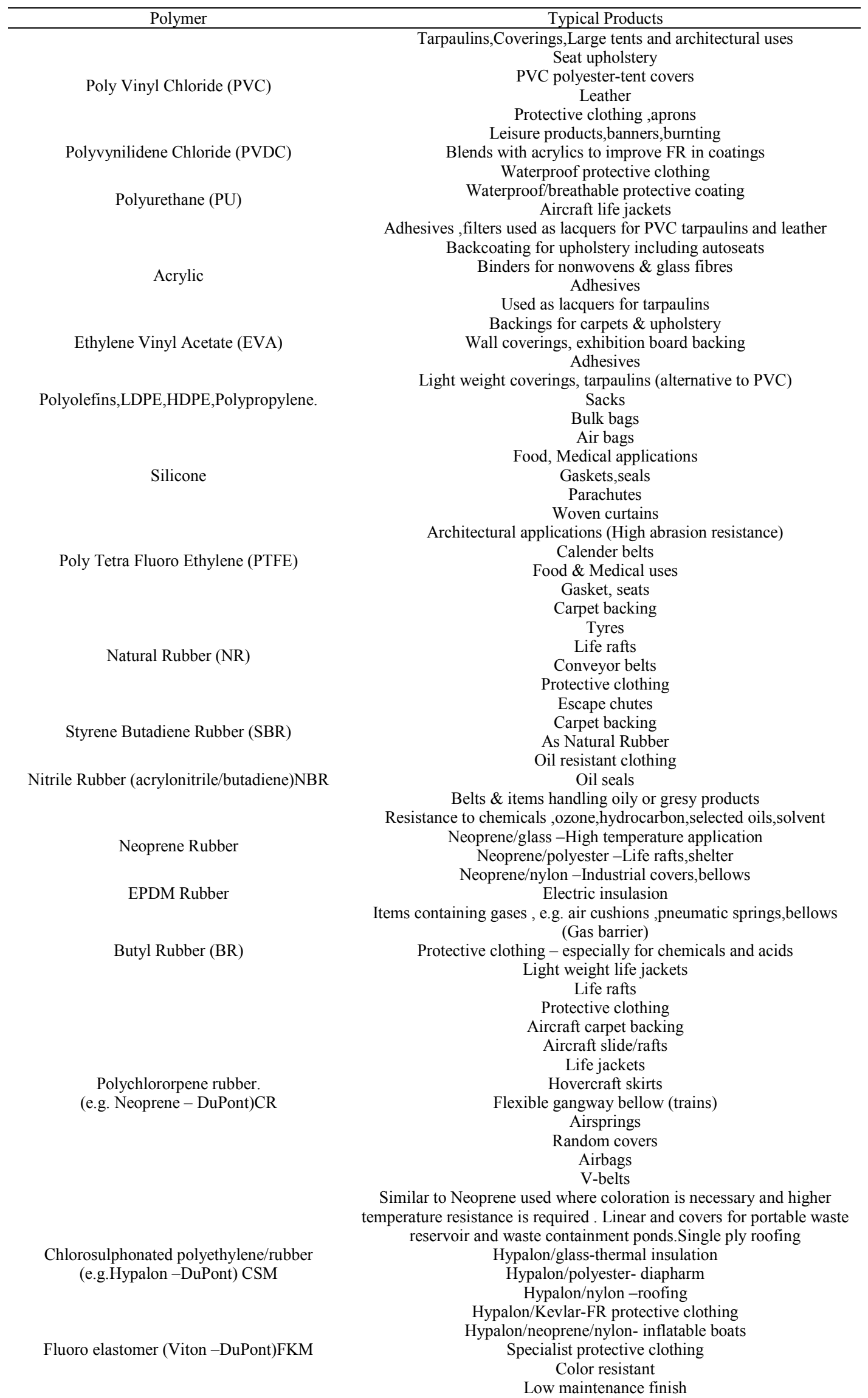


Exellent abrasion resistance

Seals substrate from moisture resistance

Modified vinyl acetate Nitrile

Styrene/Acrylic

Butadiene

Vinididiene
Tapes

Belting ,tapes,gaskets

Building products

Tapes,footwears, gaskets, binder,labels Electric paper

Table 2. Function of functional properties of different coating composition[8-10]

\begin{tabular}{|c|c|}
\hline Functional Properties & Coating chemicals \\
\hline \multicolumn{2}{|l|}{ Stain release } \\
\hline Soil release & Perfluoro chemical, Polyacrylates, Silicone based products \& PVC, \\
\hline Water repellent & Vinylacetate \\
\hline Hot oil repellent/resistance & \\
\hline \multicolumn{2}{|l|}{ Waterproof } \\
\hline Deodrant/antibacterial clean room fabric finishes, Chemicals & Poly -hexamethylene biguanide hydrochloride-PHMB,Cyclo dextrin \\
\hline Chemical odour absorbing & Activated carbon based coatings. \\
\hline Chemical protective & Based on Aramide,Teflon, PTFE,Carbon, Neoprene Coating \\
\hline Breathable coating & Hydrophilic, polyacrilamide based products,Polyurethanes \\
\hline Thermal resistance \& insulating & PVC,Teflon,Carbon coating,Silicon rubber \\
\hline Heat \& corrosive resistant coating & Polytetrafluoroethylene,Perfluorooctanoic acid,Teflon \\
\hline Stiffness/interlining coating & LDPE/HDPE/PVC \\
\hline $\begin{array}{c}\text { Solvent resistance, abrasion resistance, ageing resistance,ozone } \\
\text { resistance }\end{array}$ & Polyurethane coating \\
\hline Waterproofing, electrical encapsulasion, sealants & Butadiene polyurethane resin \\
\hline
\end{tabular}

It is important to realize that coating formulations consists of several additives. Amongst these are UV radiation and heat stabilizers, antioxidants, fillers to improve the mechanical properties, fillers for economy, FR chemicals, reinforcement fibers (turning the plastic into a 'Composite'), pigments and other compounds necessary to confer further special properties or to assist with processing[9]. It is necessary to make sure that all the ingredients are compatible with each other.

The formulation of water-proof coating is become very popular in the recent uses of demand and for example; some typical formulations of coatings are as follows;

Table: 3 Formulation of water proof coating using Polyurethane solvent-based resins[11]

Polyurethane (granular form) - 30\%., Polyisocyanate crosslinking agent or Melamine formaldehyde resin type and Acid catalyst

Table 3. Typical formulation of PVC based coating is as follows[12-13]

\begin{tabular}{cc}
\hline PVC & $40 \%$ \\
Filler(CaCO3) & $35 \%$ \\
Primary Plasticiser & Dioctyl phthalate \\
Secondary Plasticiser & Carboxy Pardtin Wax \\
Solvent & Ketone/DMT \\
\hline
\end{tabular}

\section{Types of Coating Methods}

There are several processes for the application of coating to the textile material depending upon the requirement of end product. Some of these processes are described below:

\subsection{Direct Coating}

The simplest coating procedure is the direct method, sometimes called the 'floating knife' or knife over air tech- nique where the fabric is stretched flat to form an even uniform surface and is transported under a stationary doctor blade[13]. As the fiber moves forward, it is scraped by the knife and the polymer resin compound is spread evenly over the surface as per Fig.1 \&Fig.2. These show the knife or blade over roller method of direct coating. The amount of polymer applied, the 'add-on'[14] depends on the concentration of dispersion or solution- this is the so-called 'solids content'; other parameters also affect resin add-on as will be seen.

Uses: Generally fairly tightly woven fabrics capable of being pulled flat and uniform can be coated by the direct method. Waterproof protective clothing fabric, automotive car seat fabrics, tarpaulins and light weight material for inflatable are produced by the direct method.

\subsection{Foamed and Crushed Foam Coating}

This method can be used to apply polymer to woven fabrics and knitted fabrics and also to fabric produced from spun yarns or fabrics of a general open construction which cannot generally be direct coated. This is possible because the foam, which is rather like shaving cream, sits on the top of coating. Crushed foam coating increases the no. of fabrics which can be coated; it also greatly reduces penetration of resin into the fabric, which allows the production of much softer handles and better drape than can generally produced by direct coating[14]. This technique is used for apparel goods, floor coverings, wall coverings ,black-out curtains and curtain linings and filter materials.

\subsection{Transfer Coating}

The principle of transfer coating is first to spread the polymer on to release paper to form a film and then to laminate this film to the fabric. The process is divided in few 
steps like;

- Coat the resin (which will become the top layer) on to the transfer paper and evaporate off the solvent.

- Coat on the second layer, which will become the base layer (and is actually the adhesive which joins the top layer to the fabric).

- Lay the fabric on top of the coating, nip together, evaporate the solvent and crosslink the two layers together.

- Peel the coated fabric off the release paper[15-17].

The main uses of this type of coating technique are the transfer coated polyurethane fabrics is in up-market and the waterproof protective clothing. Other outlets for transfer coated polyurethane include upholstery, luggage, footwear, gloves and waterproof mattress covers. Woven velvet automotive seat fabric is sometimes processed in this way to lock in the pile. Carpets and other articles are also processed using back licking techniques.

\subsection{Hot Melt Extrusion Coating}

This method is used for thermoplastic polymers such as polyurethane, polyolefins and PVC, which are applied by feeding granules of the material into the nip between moving heated rollers. There are two general designs in use, the Zimmer machine, which has two melt rollers the Bema machine, which has three[18-20]. They are smaller version of calenders but differ in that they need a fabric (or paper or a film) as a substrate on which to deposit the film as it is produced. This method can apply resin (in the form of films) to fabric at a faster rate than that can be achieved by transfer coating or direct coating. This process is used to produce light weight coverings or tarpaulins.

\subsection{Calender Coating}

Calenders are primarily used to produce unsupported films of PVC and rubbers from compounded polymer 'dough' . This process can also be adapted to apply freshly produced film to fabric. Calenders consist of a number of massive rollers, sometimes five or more in various configurations, which rotate to crush the 'dough' and smooth it into films of uniform thickness. The thickness of the film is determined by the gap separation of the rollers, but there is usually a limit to the thinness of films which may be produced by this method[21]. The more rollers, film produced is more accurate. Some of the rollers also generates heat, and the material is fabricated into a continuous sheet which can be brought into contact with the fabric to which it adheres.

\subsection{Rotary Screen Coating}

The rotary screen technique which applies compound to a fabric by forcing it through a cylindrical screen, it is used mainly for textile printing. The technique can also be used for coating polymer onto fabric with add-ons; it is claimed from between 5 and $500 \mathrm{~g} / \mathrm{m}^{2}$. The add-on is controlled by resin viscosity, the mesh of the cylindrical screen; the speed and the pressure of the squeegee bar inside the screen .An array of dots are pushed through the perforated screen by the squeegee bar inside the screen and by centrifugal force onto the fabric. The fabric moves at the same speed as the rotation of the rotary screen and there is, thus, no frictional contact between the two[22]. When deposited on to the fabric, the resin in the dots flows and merges together to form a continuous coating. The rotary screen method can be used to apply foamed coatings or for foam processing of fabric finishes instead of padding.

\section{Recent Development}

These are all the conventional process of coating application and formulation but in today's era the requirements of human beings has been totally changed, so research is going on to achieve human needs. Some of such achievements are phase change coatings, conductive coating, anti bacterial coating etc. After all introduction of nanotechnology has changed the thinking. Some of those are discussed below.

\subsection{Phase Change Materials}

Phase change materials (PCM) take advantage of latent heat that can be stored or released from a material over a narrow temperature range[23]. PCM possesses the ability to change their state with a certain temperature range. These materials absorb energy during the heating process as phase change takes place and release energy to the environment in the phase change range during a reverse cooling process. Insulation effect reached by the PCM depends on temperature and time. Recently, the incorporation of PCM in textiles by coating or encapsulation to make thermo-regulated smart textiles is going on.

- Working principle of PCM
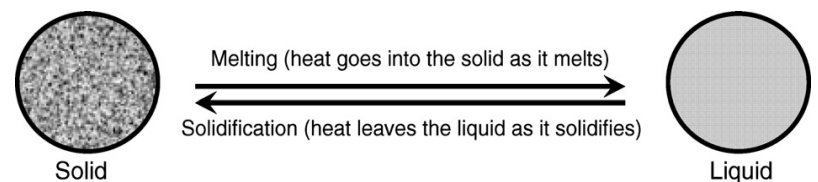

Figure 1. Change in phase change material with the change in temperature[24]

The PCMs change phases within a temperature range just above and below human skin temperature would be suitable for application in textiles. This interesting property of PCMs would be useful for making protective textiles in all-season. Fiber, fabric and foam with PCMs could store the heat body creates then release it back to body, as it needs. Since the process of phase change is dynamic (Figure 1); therefore the materials are constantly changing from a state to another depending upon level of physical activity of the body and outside temperature. The thermo-regulating characteristic is possible in manmade fiber by adding PCM microcapsules to a polymer solution prior to fiber extrusion. In the process[24], PCM microcapsules are integrated inside the fiber itself. Coating, lamination, finishing, melt spinning, bi-component synthetic fiber extrusion, molding, foam techniques are some of the convenient processes for PCMs' incorporation into the textile matrix. 
- Coatings using PCM

A coating composition for textiles includes wetted microspheres containing a phase change material dispersed throughout a polymer binder, a surfactant, a dispersant, an antifoam agent and a thickener. Preferred phase change materials include paraffinic hydrocarbons. The microspheres may be microencapsulated. To prepare the coating composition, microspheres containing phase change material are wetted and dispersed in a dispersion[25-26] of water solution containing a surfactant, a dispersant, an antifoam agent and a polymer mixture. The coating would be then applied to a textile substrate. In an alternative embodiment, an extensible fabric would be coated with an extensible binder containing microencapsulated phase change material to form an extensible, coated fabric. PCM could be incorporated into the textiles by coating using polymer such as acrylic, polyurethane, etc, and applied to the fabric. There are various coating processes available such as knife-over-roll, knife-over-air, pad-dry-cure, gravure, dip coating, and transfer coating. This technique is used in space suits, sports-wear, medical applications, shoes and accessories \& in automobile textile such as seat cover. Automobile interior applications use paraffin due to their high capacity for heat storage; lack of toxicity, corrosiveness, or hygroscopic properties; low cost; and amenability to mixing to realize the desired temperature range.

\subsection{Flame Retardancy}

Two types of microcapsules of di-ammonium hydrogen phosphate (DAHP) with respectively polyether- polyurethane shell and polyester-polyurethane shell were evaluated as intumescent flame retardant (FR) in a commercial polyurea coating for textiles. The advantages of this new concept of encapsulated FR agent are to be compatible with a polymeric matrix in order to give a permanent FR effect and to be itself an efficient FR intumescent formulation for many materials. The thermal degradation for the two types of DAHP microcapsules shows characteristics of an intumescent formulation. The reaction to fire of cotton fabrics coated by FR polyurea loaded with neat or microencapsulated DAHP was studied with the cone calorimeter as the fire model. Both types of DAHP microcapsule present in the polyurea coatings on cotton fabric give an efficient FR effect, although the char developed with microcapsules is a little less heat resistant than that developed with the pure DAHP[27]. Coatings containing microcapsules with polyester-polyurethane shells evolve the smallest quantity of smoke and $\mathrm{CO}$.

\subsection{Antibacterial Coating}

A novel antibacterial coating for cotton fabrics has been developed using core-shell particles that consist of poly (n-butyl acrylate) (PBA) cores and chitosan shells. The spherical particles are prepared via a surfactant-free emulsion copolymerization of $\mathrm{n}$ butyl acrylate in an aqueous chitosan solution induced by a small amount of t-butyl hy- droperoxide. The PBA-chitosan core-shell particles have a narrow particle size distribution with average particle diameter of approximately $300 \mathrm{~nm}$, and display highly positive surface charges. Transmission electron microscopic (TEM) images clearly reveal well-defined core-shell morphology of the particles where PBA cores are coated with chitosan shells. The particle is composed of both the PBA homopolymer and the chitosan-g-PBA copolymer[28]. The cotton fabric is coated with PBA-chitosan particles by using a conventional pad-dry-cure method. The cotton treated with PBA-chitosan particles demonstrates an excellent antibacterial activity with bacterial reductions more than $99 \%$. The presence of apatite-coated $\mathrm{TiO}_{2}$ shows antibacterial activity in the presence of black light or visible light, suggesting its potential use in reducing the risk of microorganism transmission for textile applications.

\subsection{Conductive Coating}

Polypropylene (PP) and viscose (VS) textiles were modified by the in situ synthesis of a conducting polypyrrole (PPy) overlayer. To improve adhesion of the conducting layer to the textile surface, a pyrrole-functionalized silane (SP) was synthesized and bonded onto the surface before polypyrrole formation. Moreover, to introduce hydroxyl groups into the surface, $\mathrm{PP}$ was pretreated by grafting vinyltrimethoxysilane by means of a radiofrequency plasma discharge. The compromise between the influence of SP and penetration phenomenon (best conductivity after washing: wVS$0.2 \mathrm{SP} / 25 \mathrm{Py}=3 \times 10-5 \mathrm{~S} / \mathrm{square})[29]$. In the case of polypropylene the effect of pretreatment with SP is much better than for viscose, and a higher concentration of SP leads to improved fastness of the conductive layer (wmPP$0.2 \mathrm{SP} / 25 \mathrm{Py}=3 \times 10-5 \mathrm{~S} / \mathrm{square}$; $\mathrm{wmPP}-1 \mathrm{SP} / 25 \mathrm{Py}=8 \times 10-5$ $\mathrm{S} / \mathrm{square}$ ), which indicates that the coating promoted by means of SP is more favoured than for viscose.

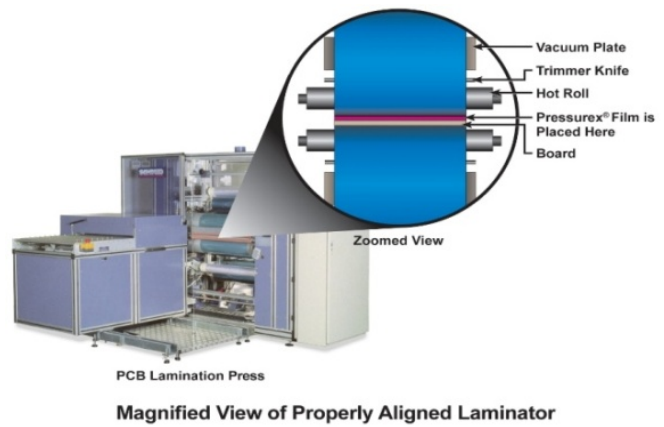

Figure 2. A broad view of different parts of lamination machine[29]

\section{Lamination}

A laminated (or combined) fabric consists of two or more layers, one of which is a textile fabric, bonded closely together by means of an added adhesive, or by the adhesive properties of one or more of the component layers. Conventional laminated technical textiles normally consist of one or more textile substrates that are combined using a pre- pre- 
pared polymer film or membrane by using adhesives or by using heat and pressure (Figure 2). Usually the layer in a laminated fabric consists of a polymeric substance; however, in some metalized fabrics the metal is not deposited by chemical deposition but is laminated using an adhesive or by use of an electric arc.

Environmental considerations have generated greater interest in hot -melt adhesives, compared with the older solvent-based adhesives, or the flame lamination technique, in which a flame melts polyurethane foam that, while molten, is pressed in contact with the textile. Adhesion in lamination may be over the whole fabric surface or of the discrete type[1-3]. Here the adhesive is applied as a thermo-fusible resin in the form of a dot coating that imparts greater flexibility and less stiffness to the laminate, factors important in subsequent molding applications.

\subsection{Lamination Theory in Brief}

A new first-order shear deformation theory (FSDT) and sandwich plates has been developed and verified for laminated plates and sandwich plates. Based on the definition of Reissener - Mindlin's plate theory, the average transverse shear strains, which are constant through the thickness, are improved to vary through the thickness. It is assumed that the displacement and in-plane strain fields of FSDT can approximate, in an average sense, those of three-dimensional theory. Relationship between FSDT and three-dimensional theory has been systematically established in the averaged least-square sense. This relationship provides the closedform recovering relations for three-dimensional variables expressed in terms of FSDT variables as well as the improved transverse shear strains. This makes two main contributions. First an enhanced first-order shear deformation theory (EFSDT) has been developed using an available higher-order plate theory. Second, it is shown that the displacement fields of any higher-order plate theories can be recovered by EFSDT variables. The present approach is applied to an efficient higher-order plate theory[26-27]. Comparisons of deflection and stresses of the laminated plates and sandwich plates using present theory are made with the original FSDT and three-dimensional exact solutions. A refined nonlinear zigzag shear deformation theory of composite laminated plates is presented using a modified mixed variational formulation. The theory accounts for continuous piecewise layer-by-layer linear variation approximation in the thickness direction for the displacements. Moreover, it includes piecewise stress distributions satisfying the continuity conditions at the layer interfaces and the surface conditions. The advantages of this theory are that it recovers the interlaminar stresses, and does not need any shear correction factor used in other first-order theories. To assess this theory, the bending problems of symmetric and anti symmetric cross-ply laminated plates are solved. Some numerical results for the deflection and stresses are compared with their counterparts obtained due to three- dimensional elasticity solution and higher-order laminate theories.
In the classical theory of plates (CPT), it is assumed that plane sections initially normal to the mid surface before deformation remain plane and normal to that surface after deformation. This is the result of neglecting transverse shear strains. However, non-negligible shear deformations occur in thick and moderately thick plates and the theory gives inaccurate results for laminated plates. So, it is obvious that transverse shear deformations have to be taken into account in the analysis. First order shear deformation theory (FSDT) and takes the displacement field as linear variations of midplane displacements. In this theory, the relation between the resultant shear forces and the shear strains is affected by the shear correction factors. This method has some advantages due to its simplicity and low computational cost. Some another plate theories, namely, higher order shear deformation theories (HSDT),[29] which include the effect of transverse shear deformations provided a simple higher- order theory which accounts not only for transverse shear strains but also for a parabolic variation of the transverse shear strains through the thickness.

\subsection{Flame Lamination}

Flame lamination can be used to adhere polyurethane foam to a textile material. A web of

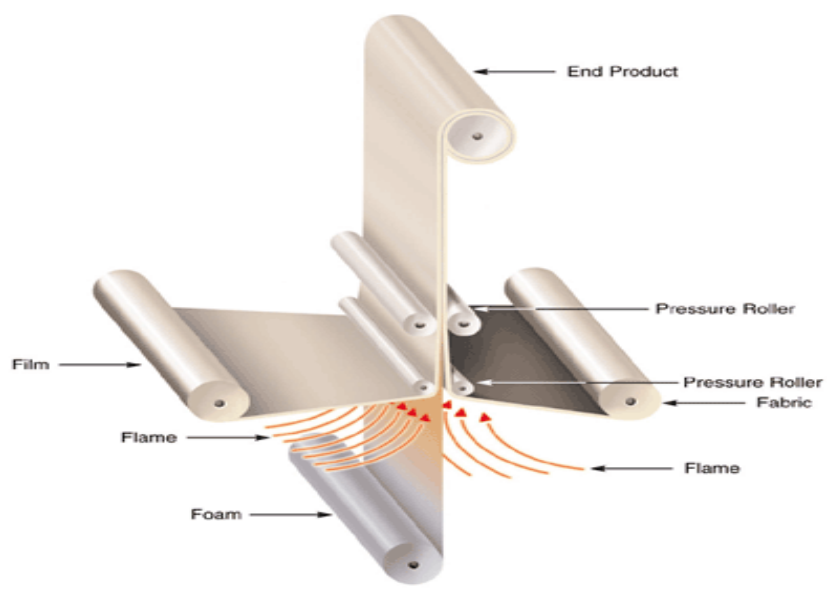

Figure 3. Process of flame lamination[30]

Polyurethane (P.U.) foam from a supply roller is passed over a gas flame at around $950^{\circ} \mathrm{C}$ and combined with the textile material from a second roller in the first nip of a three-bowl system[30]. The foam-laminated textile material is then passed through the second nip and wound up on a third roller (Figure 3). Three-ply laminates are possible by the addition of a second burner to the machine. The major disadvantage is the high capital cost of equipment-for instance, carbon filter absorbers are needed to clean up the gaseous emissions so that they comply with legislative requirements. Flame lamination has been widely used for automotive fabrics.

\subsection{Adhesive Lamination-aqueous Based}

Adhesive lamination can be used to laminate two fabrics by applying an aqueous-based pressure-sensitive adhesive 
by knife-over-roller spreading. Alternatively, the pressure-sensitive adhesive can be spread on a release paper and then transfer coated to the textile material, which can then be combined with a second fabric by bringing these into contact under heat and pressure to remove the water[21]. Typical of the adhesives used are natural and synthetic rubber, styrene-butadiene resins (SBRs), polyvinyl alcohol and acrylic polymers (Figure 4).

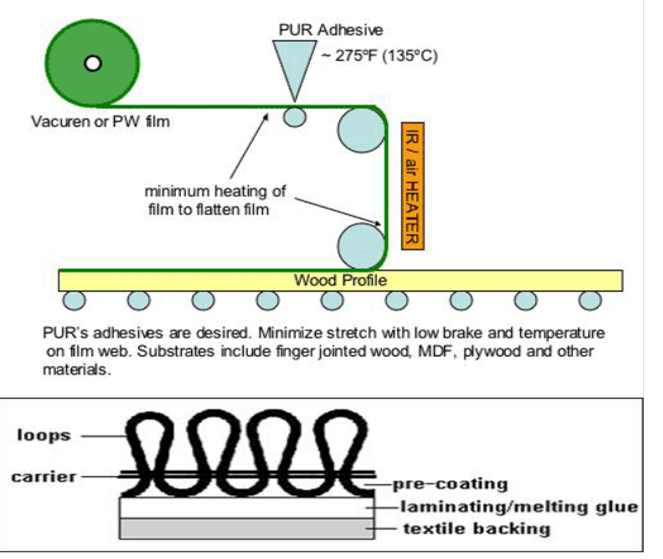

Figure 4. Process of adhesive lamination[21]

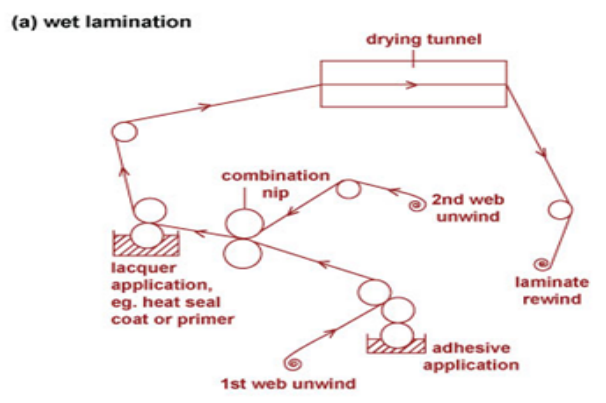

(b) dry lamination

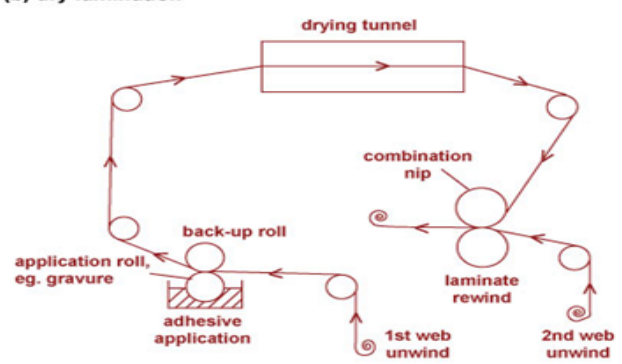

Figure 5. Process of adhesive lamination-solvent-based[31]

A second method of applying aqueous-based adhesives using hot -melt polymers is to use rotary screen-printing. The water is evaporated using infra-red heating, the polymer is melted and a second layer of material brought into contact with it to create bonding. Aqueous-based adhesives such as ethylene vinyl acetate, polyethylene, polyamide, polyesters and polyurethane can be used, and the adhesives may be foamed, applied in a specific pattern, and spread by a second blade after the print head[24-25]. A softer handle with greater breathability can be obtained using this technique, but heat-sensitive textile materials may be difficult to control. Typical uses of this type of technique products include blackout curtains and blinds, and disposable hospital ap- parel.

\subsection{Adhesive Lamination-solvent-based}

Solvent-based adhesives can be used to laminate micro-porous membranes to textile fabrics to provide a barrier against liquids (for use in hospital theatre gowns and to protect mattresses, for instance)[31]. Solvent-based polyurethane that cures in the presence of moisture is sprayed on the fabric and the membrane is nipped against the adhesive surface (Figure 5). Then the two are held together while cross-linking takes place to form the necessary bonding. Engraved roller or screen-printing techniques may also apply solvent-based adhesives.

\subsection{Heat Lamination}

Heat lamination using a coating or hot -melt adhesive supplied as a solid, or slit film net or web can be carried out on the surface of a heated central drum (180-250[degrees]C) where the materials are held together as a two-ply composite under a tensioned continuous pressure blanket[7]. Flatbed laminating machines can also be used, but the method is unsuitable for heat-sensitive fabrics (Figure 6). Heat lamination has been widely used for heat-sensitive fabrics.

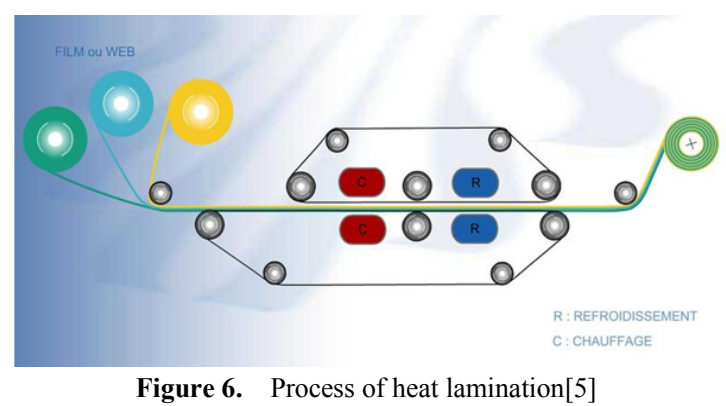

\subsection{Hot -melt Adhesives}

Hot -melt adhesives are thermoplastic and can be melted or softened by heat. When spread on the fabric in the hot state, lamination with another fabric can occur on re-solidification as the coating cools down. A variety of methods can be used with hot -melt adhesives. Slot die extrusion allows high viscosity hot -melt adhesives to be extruded as a continuous film directly on all types of textiles. Mixing the ho-melt adhesive with air inside. Alternatively, roller and calender hot -melt coating and laminating may be used. Hot -melt adhesive, ground down to $60-200[\mathrm{mu}] \mathrm{m}$ particle size can be applied from an engraved roller (at $250^{\circ} \mathrm{C}$ or above) in a predetermined pattern to a heat-stable fabric (Figure 7). Then a second fabric or film is brought into contact while the adhesive is still molten[23]. In another application method, adhesive is applied from a hopper placed above a card-wire covered roller that holds the powder until this is released by a vibrating wire brush. This scatter-coating method applies the powder in a discontinuous random pattern. The scatter-coated fabric may be passed into a flatbed laminator. This contains two driven belts (top and bottom) with a heating section, in which the adhesive is melted, and a cooling section, to solidify the adhesive while 
the laminate is still under pressure[25].

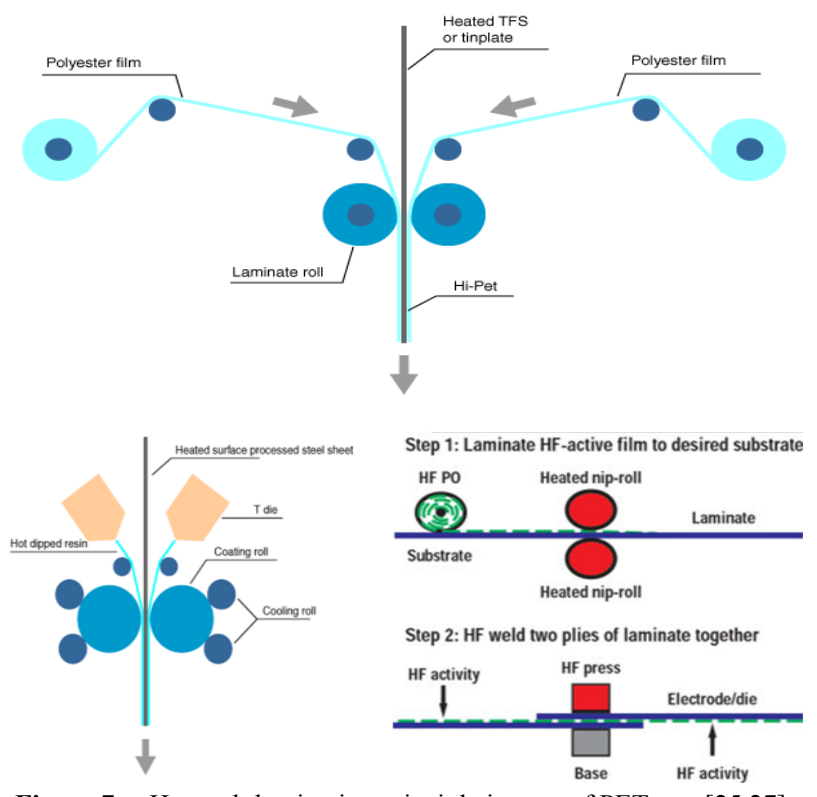

Figure 7. Hot melt laminating principle in case of PET yarn[25,27]

\subsection{Film Lamination}

Laminate film is generally categorized into these five categories (Figure 8):

- Standard thermal laminating films

- Low-temperature thermal laminating films

- Heat-set (or heat-assisted) laminating films

- Pressure-sensitive films

- Liquid laminates[5]

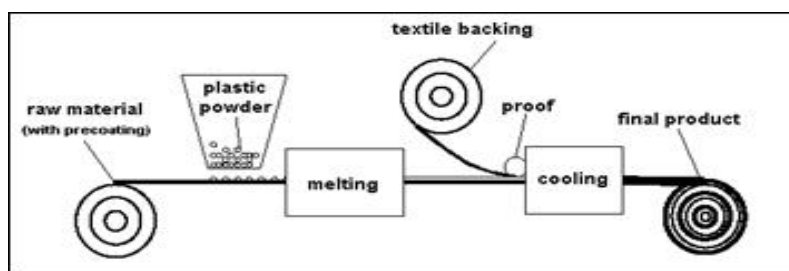

Figure 8. Working principle of film laminating machine[8]

\section{Recent Developments in Lamination Technique}

There are several modern developments is going on through in the field of coating and lamination technology with the aim of improvements of this emerging area; for example a few of them has been discussed in below;

\subsection{Manufacture of 3D Structures by Cold Low Pressure Lamination of Ceramic Green Tapes}

3D multilayer devices were generated by Laminated Object Manufacturing (LOM), a well-known rapid-prototyping technology. Divergent from this method, commercial ceramic green tapes were used which were laminated by Cold Low Pressure Lamination (CLPL). In contrast to thermo-compression, which works at pressures and elevated temperatures, CLPL allows to join particularly fine, complex structures with cavities or undercuts, because no mass flow occurs. This technique is based on gluing the adjacent tapes by means of an adhesive film at room temperature under a low pressure[16]. After binder burnout and sintering the ceramic laminate has a homogenous and dense microstructure free of interfaces. This modified LOM technique is particularly suitable for the production of Micro Electro Mechanical Systems (MEMS).

\subsection{Embedding Capacitors and Resistors into Printed Circuit Boards Using a Sequential Lamination Technique}

Embedding capacitors and resistors into printed circuit boards (PCBs) offers many benefits over surface mount technology (SMT) and through-hole packaging (PTH). These benefits include improvements in electrical performance and reliability, and potential cost reduction. Embedded devices also enable signal integrity at speeds over $1 \mathrm{GHz}$. Also, replacement of surface mounted discrete passives with an embedded passives layer allows for tighter component spacing, fewer holes and a larger routing area[32]. All these are essential for board miniaturization. However, the goals of reliability improvement (Table 4), space conservation, performance enhancement and solder joint reduction by using embedded passives can only be realized if the PCB fabricator can produce high quality boards in a practical production environment in a timely manner.

Table 4. Comparison between the continuous and discontinuous lamination techniques

\begin{tabular}{cc}
\hline Continuous Lamination (On- / Offline) [20-24] & Discontinuous Lamination (Definite-Length) [21,22] \\
\hline For rubber and plastic parts & For rubber and plastic extrusion \\
Max. lamination. speed : $15 \mathrm{~m} / \mathrm{min}$; (depending on compound) \\
Lamination of most available tapes: heat-bond / \\
pressure sensitive & $\begin{array}{c}\text { Max. lamination. speed : } 30 \mathrm{~m} / \mathrm{min} \text {; (depending on compound) } \\
\text { Lamination of most available tapes: heat-bond / } \\
\text { pressure sensitive }\end{array}$ \\
Combination equipment for heat-bond & $\begin{array}{c}\text { and } \\
\text { and pressure sensitive tapes }\end{array}$ \\
Precise tape position & Combination equipment for heat-bond and \\
Controlled lamination force & Pressure sensitive tapes \\
Controlled tape stretch & Precise tape position \\
Defined tape tension & Controlled lamination force \\
Controlled temperatures & Controlled tape stretch \\
Reliable controlled process & Defined tape tension \\
Control of the process parameter & Controlled temperatures \\
Manual - semiautomatic - automatic - robot-lamination & Reliable controlled process \\
Interface for external data log
\end{tabular}




\subsection{High-performance Polymer Photovoltaic Devices with Inverted Structure Prepared by Thermal Lamination}

Use of a lamination process for the introduction of $\mathrm{Au}$ electrode, instead of conventional metal evaporation, improved the power conversion efficiency (PCE) of inverted-structure photovoltaic devices from $1.6 \%$ to $2.6 \%$ based on a bulk hetero junction of poly(3-hexylthiophene) (P3HT) and $(6,6)$-phenyl $\mathrm{C}_{61}$ butyric acid methyl ester (PCBM). X-ray photoelectron spectroscopy indicated that a thin layer of P3HT is spontaneously formed at the air/polymer blend layer interface during the spin-coating process. It is suggested that the vacuum-evaporated gold could destroy the surface-segregated thin layer of $\mathrm{P} 3 \mathrm{HT}[10,25]$, while the lamination process preserves the surface structure working as an electron-blocking layer. The insertion of a PEDOT:PSS layer, between the metal electrode and polymer layer, in the lamination process further improved the PCE to $3.3 \%$ with a short-circuit current density of $9.94 \mathrm{~mA} \mathrm{~cm}^{-2}$, an open-circuit voltage of $0.60 \mathrm{~V}$, and a fill factor of $55 \%$ under AM1.5 $100 \mathrm{~mW} \mathrm{~cm}^{-2}$ irradiation.

\subsection{Processing of an Aqueous Tape Casting of Mesocarbon Microbeads for High-performance Carbonaceous Laminations}

Tape casting is a traditional method for the manufacture of ceramic laminations. In this study, aqueous tape casting was adopted to obtain high-performance carbonaceous laminations with homogeneous density and high strength. For the preparation of a stable and homogeneous slurry of mesocarbon microbeads, the research focuses on the rheological behavior of slurries consisting of a solvent and additives such as a binder, plasticizer and dispersant. After three to five slips of casting tape laminated together under 40 $\mathrm{MPa}$ at $85^{\circ} \mathrm{C}$ and sinter heated to $1400{ }^{\circ} \mathrm{C}$ for $1 \mathrm{~h}$ at a given heating ratio, carbonized laminations are obtained with an average density of $1.66 \mathrm{~g} / \mathrm{cm}^{3}$, a bending strength of 82.76 $\mathrm{MPa}$ and an electrical conductivity of $169.2 \mathrm{~S} / \mathrm{cm}$. During sintering of green laminations, the additives are pyrolyzed at $500{ }^{\circ} \mathrm{C}$ to form amorphous carbon[28], which reduces the electrical conductivity and the mechanical strength of the carbonized laminations. However, by controlling the total additive content of the slurries, the influence of the additives can be reduced to a minimum.

\subsection{Novel Cold Chemical Lamination Bonding Tech- nique-A simple LTCC Thermistor-based Flow Sensor}

Lamination is a quality determining processing step in fabrication of LTCC multilayer devices for packaging, fluidic microsystems, and sensors. DM765E distilled water dilution was applied, using a paint brush, on a top surface of a green ceramic piece. The gluing process was carried out at low pressure about $15 \mathrm{MPa}$ at room temperature, achieving good bonding quality. The method is dedicated to water-based slurries. The common LTCC tape bonding method is thermo-compression. The tapes are joined at high temperature, up to $80^{\circ} \mathrm{C}$, and pressures, up to $30 \mathrm{MPa}$, for $2-15$ $\min$. The temperature softens the tapes, facilitating pressure bonding. This method has several advantages: thermo-compression gives good encapsulation of the final device, strong bonding $[25,26]$, and allows the resulting structure to have more than 40 layers. However, there is one important problem: high pressure and temperature cause deformation of the manufactured structure. The main advantage of this technique is that the bond is made at room temperature and low pressure, about $5 \mathrm{MPa}$, thereby decreasing the deformation of the chambers and channels. However, it also has disadvantages: the increase of pressure in the chamber during firing destroys modules with closed chambers, and the laminated stack may crack during the firing process. The method is therefore best used for making open chambers and channels.

\section{Lamination Faults}

There some faults can be usually appears in the laminated products during the process. This faults can be removed or partially decreased by a proper $\mathrm{m} / \mathrm{c}$ setting, controlling different parameters like; heating, temperature, degree of adhesion limit etc. Few of the lamination faults which generally frequently appears in lamination process have been discussed in below (Table 5);

\section{Conclusions}

The coating and lamination gives a powerful tool for the advancement of textile technology. It provides the opportunities to produce the special fabrics like water-proof resistant tarpaulins, coverings, large tents and architectural uses, backcoating for upholstery including autoseats, Food, Medical applications, parachutes, Woven curtains, for heatsensitive fabrics, automotive fabrics, disposable hospital apparel etc. the recent developments also enhanced the lamination and coating technique into state-of-art process of the future in textile field.

Table 5. List of some common lamination fault in textile finishing $[11,12,18]$

\begin{tabular}{|c|c|c|}
\hline Faults name & Reasons & Remedies \\
\hline Bubbles & Improper roller nip pressure & Proper roller surface mapping \\
\hline Particles & Poor mixing of laminating pest & Excellent grinding of the materials in the laminating pest \\
\hline Age cracks & In stability of the laminating pest/solution/adhesives & Advanced camera technology for highest contrast \\
\hline Misalignment of edges & Luck of proper supervisation to the process & Easy integration into production lines \\
\hline Laminating faults & Quick process, less time & Networking for further evaluation \\
\hline
\end{tabular}




\section{REFERENCES}

[1] Ian H., 2003, Coating and lamination enhance textile performance., Ed. $3^{\text {rd }}$ Edition, Technical Textiles International.

[2] Mondal. S., 2008, Phase change materials for smart textiles An overview, Applied Thermal Engineering., 28, $1536-1550$.

[3] Stephen, G., Serge, B., Meryline, R., Isabelle, V., Lan, T., Rene, D., and Frank, P., 2005, Flame retarded polyurea with microencapsulated ammonium phosphate,, Polymer Degradation \& Stability, 88, 106-113.

[4] Weijun, Y.L., Fai, M., John, X., Leung, T., Kam, L.D., and Pei, L., 2005, Novel Core -shell particles with poly (n-butyl acrylate) cores \& chitosan shells as an antibacterial coating for textiles, Polymer, 46, 10538-10543.

[5] Kangwansupamonkon,Vichuta ,Suvimol(2009) Antibacterial effect of apatite-coated titanium dioxide for textiles application,Nanomedicine:Nanotechnology,Biology \& Medicine, Vol 5,Pages 240-249.

[6] Matejmicusik, T., Igor, M., Katarina, F., and Mohamed, 2007, Conductive polymer coated textiles: The role of fabric treatment by pyrrole-functionalised triethoxySilane., 157, 914-923.

[7] Bidoki, S.M., and Wittlinger, R., 2010, Environmental and economical acceptance of polyvinyl chloride (PVC) coating agents., Journal of Cleaner Production, 18(3), 219-225.

[8] Krebs, F.C., 2010, Fabrication and processing of polymer solar cells: A review of printing and coating techniques., Solar Energy Materials and Solar Cells, 93(4), 394-412.

[9] Mondal. S., 2008, Phase change materials for smart textilesAn overview., Applied Thermal Engineering, 28(11-12), $1536-1550$

[10] Krebs, F.C., 2009, Fabrication and processing of polymer solar cells: A review of printing and coating techniques., Solar Energy Materials and Solar Cells, 93(4), 394-412.

[11] Covarel, G., Bensaid, B., Boddaert, X., Giljean, S., Benaben, P., and Louis, P., In Press, Corrected Proof, Available online 1 October 2011, Characterization of organic ultra-thin film adhesion on flexible substrate using scratch test technique., Surface and Coating Technology.

[12] Gross, M.E., and Martin, P.M., Chapter 11 - Vacuum Polymer Deposition, Handbook of Deposition Technologies for Films and Coatings (Third Edition), 2010, Pages 532-553.

[13] Chang, H.Y., Tzeng, W.J., Lin, C.H., and Cheng, S.Y., 2011, Ionic compounds lamination reaction and characteristics of photosensitive copper indium sulfide on titania nanotube arrays., Journal of Alloys and Compounds, 509, 35(1), 8700-8706.

[14] Nakamura, M., Yang, C., Tajima, K., and Hashimoto, K., 2009, High-performance polymer photovoltaic devices with inverted structure prepared by thermal lamination., Solar Energy Materials and Solar Cells, 93(9), 1681-1684.

[15] Park, H., Moon, H., Park, S., Lee, J., Yoon, D., Hyun, S., and
Kim, D., 2010, Performance improvement of anode-supported electrolytes for planar solid oxide fuel cells via a tape-casting/lamination/co-firing technique., Journal of Power Sources, 195, 9(1), 2463-2469.

[16] Fern, N., Alam, P., Touaiti, F., and Toivakka, M., 2012, Fatigue life predictions of porous composite paper coating., International Journal of Fatigue, 38, 181-187.

[17] Saxena, K., Mehta, D. S., Rai, V. K., Srivastava, R., Chauhan, G., and Kamalasanan, M.N., 2008, Implementation of anti-reflection coating to enhance light out-coupling in organic light-emitting devices., Journal of Luminescence, 128(3), 525-530.

[18] Natural wood effect with UV curable powder coatings., Focus on Powder Coatings, Volume 2008, Issue 11, November 2008, Pages 2-5.

[19] Reid, R.G., and Paskaramoorthy, R., 2011, An extension to classical lamination theory for use with functionally graded plates., Composite Structures, 93(2), 639-648.

[20] Chang, Y., Chen, C.Y., Luo, F.T., Chao, Y.C., Meng, H.F., Zan, H.W., Lin, H.W., Horng, S.F., Chao, T.C., Yeh, H.C., and Tseng, M.R., 2012, Vacuum-free lamination of low work function cathode for efficient solution-processed organic light-emitting diodes., Organic Electronics, 13(3), 388-393.

[21] Bailey, B.A., Reese, M.O., Olson, D.C., Shaheen, S.E., and Kopidakis, N., 2011, Air-processed organic photovoltaic devices fabricated with hot press lamination., Organic Electronics, 12(1), 108-112.

[22] Buchegger, W., Wagner, C., Svasek, P., Lendl, B., Kraft, M., and Vellekoop, M.J., 2011, Fabrication and characterization of a vertical lamination micromixer for mid-IR spectroscopy., Sensors and Actuators B: Chemical, 159(1), 336-341.

[23] Shafique, M.F., Laister, A., Clark, M., Miles, R.E., and Robertson, I.D., 2011, Fabrication of embedded microfluidic channels in low temperature co-fired ceramic technology using laser machining and progressive lamination, Journal of the European Ceramic Society, 31(13), 2199-2204.

[24] J.R. Wagner Jr., 2010, Chapter 9 - Blown film, cast film and lamination processes., Multilayer Flexible Packaging, 2010, 107-112.

[25] Bishop, C.A., 2011, Products Using Vacuum Deposited Coatings, Vacuum Deposition onto Webs, Films and Foils (Second Edition), 2011, 13-51.

[26] Tsukamoto, H., 2010, Design of functionally graded thermal barrier coatings based on a nonlinear micromechanical approach., Computational Materials Science, 50(2), 429-436.

[27] Teisala, H., Tuominen, M., Aromaa, M., Makela, J.M., Stepien, M., Saarinen, J.J., Toivakka, M., and Kuusipalo, J., 2010, Development of superhydrophobic coating on paperboard surface using the Liquid Flame Spray., Surface and Coatings Technology, 205(2), 436-445.

[28] Poultney, D., Snell, D., 2008, Use of the Fourier transform infrared (FTIR) technique for determination of the composition of final phosphate coatings on grain-oriented electrical steel., Journal of Magnetism and Magnetic Materials, 320(20), e649-e652.

[29] Niu, L., Cheng, Y.F., 2008, Development of innovative coating technology for pipeline operation crossing the per- 
mafrost terrain., Construction and Building Materials, 22(4), 417-422.

[30] Ke, X.B., Zheng, Z.F., Zhu, H.Y., Zhang, L.X., and Gao, X.P., 2009, Metal oxide nanofibres membranes assembled by spin-coating method., Desalination, 236(1-3), 1-7.

[31] Bang, G., and Kim, S.W., In Press, Corrected Proof, Available online 21 December 2011, Biodegradable poly(lactic acid)-based hybrid coating materials for food packaging films with gas barrier properties., Journal of Industrial and Engineering Chemistry.

[32] Fang, Y., Eames, P.C., Norton, B., Hyde, T., Huang, Y., Hewitt, N., 2008, The thermal performance of an electrochromic vacuum glazing with selected low-emittance coatings., Thin Solid Films, 516, Issue 6(30), 1074-1081. 